\title{
Brachydactyly-nystagmus-cerebellar ataxia syndrome
}

INSERM

\section{Source}

INSERM. (1999). Orphanet: an online rare disease and orphan drug data base.

Brachydactyly-nystagmus-cerebellar ataxia syndrome. ORPHA:1246

Brachydactyly-nystag mus-cerebellar ataxia syndrome is characterized by brachydactyly, nystagmus and cerebellar ataxia. Intellectual deficit and strabismus are also reported in some patients. 